\title{
Constant real expenditure policy: the macroeconomic impacts of budget composition and a primary surplus
}

Emerson Luís Lemos Marinho and Mauricio Benegas

\section{Abstract}

This paper analyses the fiscal policy of constant real expenditure recently adopted by Brazil's fiscal authorities. It also compares the policy of maintaining a primary surplus as a proportion of gross domestic product with that of changing the composition of spending in favour of investment in order to identify which of the two policies is more efficient in promoting economic growth. We investigate the effects of these policies on long- and short-term consumption, investment, labour supply and output and the reaction of the term structure of interest rates. We also analyse the relationship between these fiscal policies and welfare. We use a representative agent model of intertemporal utility maximization subject to budget constraint, with perfect foresight and an infinite horizon.

\section{Keywords}

Fiscal policy, public expenditure, economic conditions, consumption, investment, interest rates, social welfare, economic analysis, Brazil

\section{JEL classification}

$$
\mathrm{E} 1, \mathrm{E} 2, \mathrm{H} 3
$$

Authors

Emerson Luís Lemos Marinho is a professor with the Department of Finance of the Federal University of Ceará (UFC), Brazil. Email: emarinho@ufc.br.

Mauricio Benegas is a professor with the Department of Economics of the Federal University of Ceará (UFC), Brazil. Email: mauricio_benegas@caen.ufc.br. 


\section{Introduction}

In recent years, Brazil has faced one of its worst recessions since gross domestic product (GDP) began to be measured in the country. Moreover, the government budget deficit has worsened over time, meaning that the country may face serious difficulty in financing this deficit if urgent measures are not adopted.

Statistical analysis shows that during the period of significant growth in the primary deficit, the country's main socioeconomic indicators worsened substantially. According to data from the Institute for Applied Economic Research (IPEA, 2016), from July 2011 to September 2016, primary accounts dropped sharply from a surplus of $3.57 \%$ of GDP to a deficit of $3.05 \%$ of GDP. The real GDP growth rate of $3.4 \%$ in the third quarter of 2011 fell to $-4.84 \%$ in the fourth quarter of 2015 . In the context of this recession, inflation increased from 6.08\% to 11.28\% between 2011 and 2015.

This situation weighed heavily on families' economic conditions. The unemployment rate, for example, increased from 7.9\% in March 2013 to 13.7\% in March 2017 and the real wage mass contracted by approximately 10 billion reais between 2015 and 2016 .

With a view to addressing this problem, the fiscal authorities recently adopted a policy on constant real public spending for the coming years, according to which the nominal expenditure for a given year shall be, at most, equal to that of the previous year plus inflation in that period.

Considering the difficulties faced, this article aims to analyse the potential consequences of this policy for equilibrium trajectories for long- and short-term consumption, investment and output, and the reaction of the term structure of interest rates. The analysis of the latter is paramount considering its importance in conveying macroeconomic policies.

However, some Brazilian economists have argued that the fiscal authorities should also adopt a policy of maintaining a primary surplus as a proportion of GDP, in order to tackle the fiscal deficit and accelerate economic growth immediately. Meanwhile, other economists in Brazil believe that the government should alter its budget composition to reflect more investment in infrastructure than in expenditure. ${ }^{1}$ This infrastructure would enable private companies to increase their productivity, thus contributing to faster economic growth.

The main goal of this article is to determine, on the basis of the assumption that total government spending in real terms remains constant, which of the two fiscal policies suggested is more effective in producing higher levels of output and investment in the long term, and ultimately, produces greater economic growth.

Several papers have focused on the impact of fiscal policies on the term structure of interest rates. With regard to the use of the traditional approach of IS-LM models with some variations, we should mention the works of Blanchard (1981), Turnovsky and Miller (1984) and McCafferty (1986). In a different context that considers the intertemporal optimization behaviour of a representative agent, we should also mention the articles of Cox, Ingersoll and Ross (1985) and Fisher and Turnosvky (1992).

This article is based on the Fisher and Turnovsky model (1992) with two main alterations. The first assumes that real government expenditure is constant through time. The second suggests that the fiscal policy adopted by the government is a primary surplus as a percentage of GDP. This representative agent model employs intertemporal utility maximization subject to budget constraint with perfect foresight and an infinite horizon.

Given that financial portfolio assets may be adjusted instantly and without cost, the real economic performance is independent of the long-term interest rate, while the short-term equilibrium determines

\footnotetext{
1 Baxter and King (1993) calibrate a real business cycle model to derive the transitional dynamic response of consumption, investment and employment to changes in the composition of government spending.
} 
the short-term interest rate. As a result, the long-term interest rate is set through arbitrage between short- and long-term equilibria. Therefore, the short-term interest rate responds to fiscal policy shocks immediately, while the long-term rate responds indirectly through the effects of current and future expectations of short-term rates.

In this situation, two types of fiscal policy shock shall be considered: the first is a permanent shock unanticipated by agents; in other words, an immediate shock. The second is a permanent shock anticipated in the future. In this case, the government announces that it will alter the fiscal policy at some point in the future. In addition to the assumption that real government expenditure will remain constant through time, two fiscal policy measures shall be analysed. The first examines how changes in the composition of public expenditure (e.g. more government spending on consumption or on infrastructure) affect investment, private consumption, output, labour supply and long- and short-term interest rates. The second measure, aligned with the first, analyses the impact of growth in the primary surplus as a percentage of GDP.

Finally, this paper discusses the relationship between these fiscal policies and social welfare. The model has been built according to certain specifications in order to obtain objective results. In particular, it is assumed that the representative utility function follows the specification adopted by Christiano, Eichenbaum and Rebelo (2011) and that the technology applied is the Cobb-Douglas production function for public expenditure, as suggested by Barro (1990). With these specifications, fiscal austerity and budget composition policies that maximize social well-being are measured through the total discounted utility. It is therefore demonstrated that under reasonable conditions, a budget composition which maximizes welfare should allocate most resources to infrastructure and that the proportion of GDP allocated to the primary surplus depends on the sensitivity of per capita income to fiscal results.

Including the introduction, this article is divided into six sections. Section II introduces and discusses the applied theoretical model. Section III analyses transactional equilibrium dynamics when the government announces changes in the composition of its expenditure and increases the primary surplus as a proportion of GDP. Section IV discusses the impacts of these fiscal policies on the term structure of interest rates. Section $V$ draws some conclusions on agents' welfare when the government alters the composition of its spending and increases its primary surplus as a percentage of GDP. And lastly, section VI discusses the conclusions. There is also an annex that formally demonstrates the solutions to the model and some of the algebraic equations applied to obtain results.

\section{The theoretical model}

The model considers a closed economy ${ }^{2}$ in which identical agents assumed to have an infinite life make immediate decisions on consumption $c(t)$ and labour $l(t)$, seeking intertemporal maximization of future utility flows $U\left(c(\mathrm{t}), l(t), g_{c}(t)\right)$ discounted at a rate $\rho$. The term $g_{c}(t)$ represents government consumption expenditure. The instant utility function of the agent is defined in the additive form as: $u(c(t), l(t))+v\left(g_{c}(t)\right)$, in which, $u$ and $v$ are strictly concave forms with the following properties: $u_{c}>0$, $u_{c c}<0, u_{l}<0, u_{l l}<0, v^{\prime}>0$ and $v^{\prime \prime}<0 .{ }^{3}$

Following Barro (1990), the production function shall be defined in the multiplicative form as: $y(t)=f(k(t), l(t)) h\left(g_{i}(t)\right)$, where $y(t)$ is real output, $k(t)$ is physical capital stock, $l(t)$ is labour supply and $g_{i}(t)$ is government infrastructure spending. The production function is neoclassical with the following properties: $f$ is linearly homogeneous with $f_{k}>0, f_{l}>0, f_{k k}<0, f_{l l}<0$ and $h^{\prime}>0, h^{\prime \prime}<0$.

\footnotetext{
2 See Agénor (2005) for a model based on an open economy.

3 See Aschauer (1988, 1989 and 1990) for justification of this approach.
} 
In principle, government spending on infrastructure exerts a positive externality on the marginal productivity of private capital. In fact, the marginal productivity of private capital is given by $f_{k} h\left(g_{i}\right)$. Since $h$ is a growing function of infrastructure spending, an increase in infrastructure raises the marginal productivity of capital. The intensity of this positive external effect depends on the specification of the production function. In general, the marginal effects of private capital and of production infrastructure spending depend once again on the specification of the production function and the link between parameters and $k$ and $g$.

Considering the budget constraint, $y(t)=f(k(t), l(t)) h\left(g_{i}(t)\right)=c(t)+i(t)+g(t)$. Hence, the capital stock evolves according to the following macroeconomic identity:

$$
\dot{k}(t)=f(k(t), l(t)) h\left(g_{i}(t)\right)-c(t)-g(t)
$$

in which $g(t)$ represents total real government expenditure and $i(t)=\dot{k}(t)$. The term $\dot{k}(t)$ represents the time-related derivative of $k(t)$.

The budget constraint faced by the government is represented by the differential equation:

$$
\dot{b}(t)=r b(t)+g(t)-T(t)
$$

where $b(t)$ is the public debt stock, $T(t)$ is the lump-sum tax revenue, $r$ is the real interest rate and $\dot{b}(t)$ is the derivative of $b(t)$ with respect to time.

Total real government spending shall be considered constant through time according to the fiscal policy rule adopted by the government. That said, total spending shall be distributed between government consumption expenditure $-g_{c}(t)-$ and infrastructure expenditure $-g_{i}(t)$. In other words, $\bar{g}=g_{c}(t)+g_{i}(t)$, where $\bar{g}$ represents the total constant expenditure assuming that $g_{c}(t)=\alpha \bar{g}$ and that $g_{i}(t)=(1-\alpha) \bar{g}$ where $0<\alpha<1$.

Additionally, the fiscal policy adjustment adopted by the government shall be the primary surplus as a percentage of GDP, which means that:

$$
T(t)-g(t)=\beta y(t)=\beta f(k(t), l(t)) h\left(g_{i}(t)\right)
$$

where $T(t)-g(t)$ represents the primary surplus and $0<\beta<1$.

Therefore, the problem of the representative agent is formally summarized as:

subject to restrictions:

$$
\max \{c, l\} \int_{0}^{\infty} e^{-\rho}\left[u(c(t), l(t))+v\left(g_{c}(\alpha \bar{g})\right)\right] d t
$$

$\dot{k}(t)+\dot{b}(t)=(1-\beta) f(k(t), l(t)) h((1-\alpha) \bar{g})+r b(t)-c(t)-\bar{g}, k(0)=k_{0} b(0)=b_{0}$ and $b(0)=b 0$.

Observe that this last restriction is generated after the algebraic manipulation of expressions (1), (2) and (3) and from the definitions of $g_{i}(t)$ and $g_{c}(t)$. The last two restrictions assume that in the initial state, the economy has a capital stock $k_{0}$ and its public debt is equal to $b_{0}$.

Hamiltonian first-order conditions of current value associated with the problem (4) are given by:

$$
\begin{gathered}
u_{c}(c(t), l(t))=\lambda(t) \\
u_{l}(c(t), l(t))=-\lambda(t)(1-\beta) f(k(t), l(t)) h((1-\alpha) \bar{g}) \\
\left.\lambda(t)(1-\beta) f_{k}(k(t), l(t)) h(1-\alpha) \bar{g}\right)=\rho \lambda(t)-\dot{\lambda}(t)
\end{gathered}
$$




$$
\begin{aligned}
& \lambda(t) r=\rho \lambda(t)-\dot{\lambda}(t) \\
& \lim _{t \rightarrow \infty} \lambda(t) e^{-\rho t} k(t)=0 \\
& \lim _{t \rightarrow \infty} \lambda(t) e^{-\rho t} b(t)=0
\end{aligned}
$$

where $\lambda(t)$ is the current marginal utility of wealth. Transversality conditions (9) and (10) are established so that the trajectories of $\lambda(t)$ and $k(t)$ are not explosive.

\section{Short-run equilibrium analysis}

Solutions targeting consumption $c(t)$ and labour supply $l(t)$ as well as marginal utility of wealth functions $\lambda(t)$ of capital stock $k(t)$ and of policy parameters $\alpha$ and $\beta$ are obtained from equations (5) and (6). Therefore, we obtain the solutions $c=c(\lambda, k, \alpha, \beta)$ and $l=l(\lambda, k, \alpha, \beta)$, in which the period of time $t$ is no longer included as a function argument for notation simplification effects. In order to analyse the effect of each of the terms $\lambda, k, \alpha$ and $\beta$ on $c$ and $l$, we use the equation systems (5) and (6). The solution to this system provides the signs for the following relations: $\frac{\partial c}{\partial k}=c_{k}<0, \frac{\partial c}{\partial \lambda}=c_{\lambda}<0, \frac{\partial c}{\partial \alpha}>0, \frac{\partial c}{\partial \beta}=c_{\beta}>0$, $\frac{\partial l}{\partial k}=l_{k}>0, \frac{\partial l}{\partial \lambda}=l_{\lambda}>0, \frac{\partial l}{\partial \alpha}=l_{\alpha}<0$, and $\frac{\partial l}{\partial \beta}=l_{\beta}<0$.

In the annex, we formally demonstrate how the expressions and respective signs of the above equations are obtained. The short-run impact of capital stock variations and the marginal utility of wealth on consumption and labour supply are as expected. Meanwhile, according to the expressions of $\frac{\partial c}{\partial k}$ and $\frac{\partial l}{\partial k}$ obtained in the system solutions, when the primary surplus as a percentage of GDP increases ( $\beta$ growth), both the increase in private consumption and the decline in labour supply slow down.

Growth in government expenditure allocated to consumption ( $\alpha$ growth) implies an increase in private consumption and a decrease in labour supply. These two outcomes are less sensitive to increases in the percentage of GDP allocated to the primary surplus ( $\beta$ growth).

Finally, the growth in the primary surplus percentage leads to an increase in private consumption and a decrease in the labour supply. With regard to the increase in private consumption, the rise in $\beta$ affects consumption through an income effect and a predominant substitution effect. Consequently, expressions (6) and (7) give rise to the expression $r=(1-\beta) f_{k} k$. In these terms, $d r / d \beta<0$. Therefore, the $\beta$ growth of triggers a fall in interest rates, causing individuals to reduce savings and increase private consumption.

\section{Long-run equilibrium analysis}

Steady-state equilibrium dynamics are obtained by replacing the function solutions $c=c(\lambda, k, \alpha, \beta)$ and $l=l(\lambda, k, \alpha, \beta)$ in differential equations (5) and (6). Therefore, we obtain the following system of differential equations:

$$
\begin{gathered}
\dot{k}=f(k, l(\lambda, k, \alpha, \beta)) h((1-\alpha) \bar{g})-c(\lambda, k, \alpha, \beta)-\bar{g} \\
\dot{\lambda}=\left[\rho-(1-\beta) f_{k}(k(\lambda, k, \alpha, \beta), l(\lambda, k, \alpha, \beta)) h((1-\alpha) \bar{g})\right] \lambda
\end{gathered}
$$


Applying $\dot{k}=\dot{\lambda}=0$ in the system above, we can obtain the steady-state equilibrium, Therefore, we have that $f(\widetilde{k}, l(\tilde{\lambda}, \widetilde{k}, g, \alpha, \beta)) h((1-\alpha) \bar{g})=c(\tilde{\lambda}, \widetilde{k}, g, \alpha, \beta)+\bar{g}$ and $(1-\beta) f_{k}(\widetilde{k}, l(\tilde{\lambda}, \widetilde{k}, g, \alpha, \beta))$ $h((1-\alpha) \bar{g})=\rho$, where the solution to the above system helps to establish equilibrium variables. The variables with a tilde $(\sim)$ represent values in a steady state. Long-run impacts of fiscal policy parameters $\alpha$ and $\beta$ on capital stock and the long-run marginal utility of wealth are given by the following relations ${ }^{4}: \partial \tilde{k} / \partial \alpha<0, \partial \tilde{k} / \partial \beta<0, \partial \tilde{\lambda} / \partial \alpha>0$ and $\partial \tilde{\lambda} / \partial \beta>0$.

Therefore, increases in $\alpha$ and $\beta$ reduce the capital stock and improve the marginal utility of wealth (reduction of long-run private consumption).

The system dynamics analysis is easier following the linearization of equations (11) and (12) around their steady-state equilibrium. Consequently, we obtain the following dynamics:

$$
\begin{gathered}
\dot{k}=w_{11}(k-\widetilde{k})+w_{12}(\lambda-\tilde{\lambda}) \\
\dot{\lambda}=-\tilde{\lambda}(1-\beta) w_{21}(k-\widetilde{k})-\tilde{\lambda}(1-\beta) w_{22}(\lambda-\tilde{\lambda})
\end{gathered}
$$

where $w_{11}=\left(f_{k} l_{k} h-c_{k}\right)>0, w_{12}=\left(f_{l} l_{\lambda} h-c_{\lambda}\right)>0, w_{21}=\left(f_{k k}+f_{k} l_{k}\right) h<0$ and $w_{22}=f_{k} l_{k} h>0$.

In the annex, we formally demonstrate that long-run equilibrium is a saddle-point type and that stable and unstable arm equations are respectively represented by: $\lambda=\widetilde{\lambda}+\frac{\left(\mu_{1}-w_{11}\right)}{w_{12}}(k-\widetilde{k})$ and $\lambda=\tilde{\lambda}+\frac{\left(\mu_{2}-w_{11}\right)}{w_{12}}(k-\tilde{k})$, where $\mu_{1}$ and $\mu_{2}$ are eigenvalues of the equation system matrixes (13) and (14). Since equilibrium is a saddle-point type, we assume, without loss of generality, that $\mu_{1}<0$ and $\mu_{2}>0$.

As demonstrated in the annex, the straight line of the stable arm presents a negative inclination while that of the unstable arm is positively inclined but with a lower inclination than the stable arm.

Designing these straight lines in the space $\lambda \times k$ considering the equilibrium characteristics of the saddle point and the properties of the stable and unstable arms, we obtain the phase diagram of this system as shown in figure 1. The SS and NN straight lines represent the stable arm and the unstable arm, respectively.

Figure 1

System phase diagram

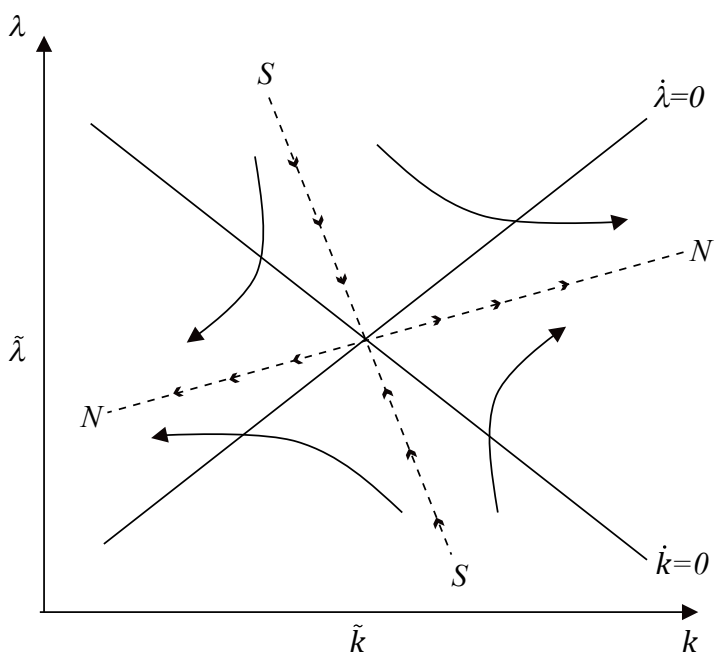

Source: Prepared by the authors.

4 These long-run relations are obtained by solving the equation systems $\dot{\lambda}=0$ and $\dot{k}=0$. 


\section{Anticipated and unanticipated permanent fiscal shocks}

In this section we analyse the consequences of two fiscal shock cases. In the first, the government announces that it will increase spending on infrastructure to the detriment of government consumption expenditure. This implies a reduction of the fiscal policy parameter $\alpha$. In the second case, the government announces a policy of growth in the primary surplus as a percentage of GDP. This results in an increase in parameter $\beta$.

In both cases, we consider that these fiscal policy announcements are not anticipated; the policy change takes place immediately. When policy changes are anticipated, the government announces that they will take place at a future time $T$. Moreover, the fiscal shocks are permanent.

The main goal is to identify which of the two fiscal policies is better for economic growth. The secondary goals are to analyse the effects of these changes on the trajectories of capital stock $k(t)$, the marginal utility of wealth $\lambda(t)$ and the term structure of interest rates. The annex includes a formal description of the solutions to the model and of how equilibrium displacements occur.

\section{Permanent fiscal shock in $\alpha$}

Initially, we consider the unanticipated fiscal policy of an increase in infrastructure expenditure (reduction in $\alpha$ ) announced by the government in the present. Since $\partial \widetilde{k} / \partial \alpha<0$ and $\partial \widetilde{\lambda} / \partial \alpha>0$, the new long-run equilibrium shall have a bigger capital stock (higher investment levels) and a lower marginal utility of wealth, which implies higher private consumption than the initial equilibrium.

Observe in figure 2A that the immediate announcement of a cut in $\alpha$ causes displacements in the lines of the stable arm XX and the unstable arm YY. Both straight lines are displaced to the right, originating a new steady-state equilibrium represented by point $\mathrm{C}$. Therefore, there is a displacement of the initial equilibrium $A$ to a new long-run equilibrium $C$.

Figure 2

A. Unanticipated shock

$\lambda(t)$

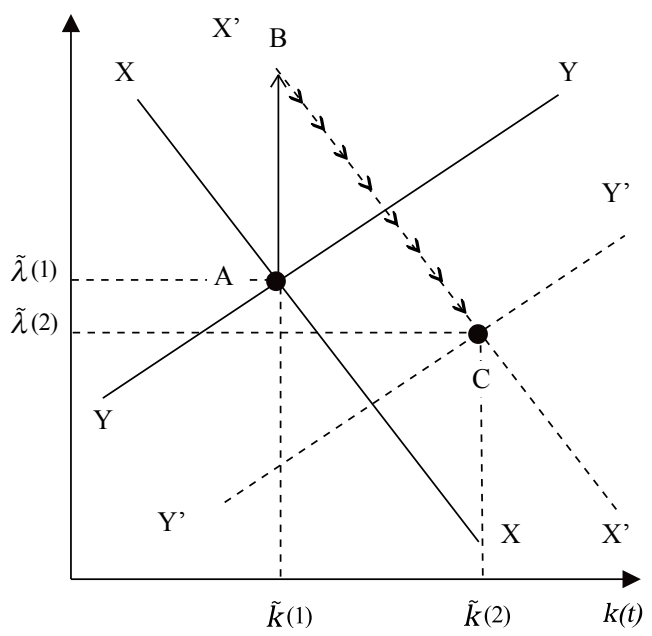

B. Anticipated shock

$\lambda(t)$

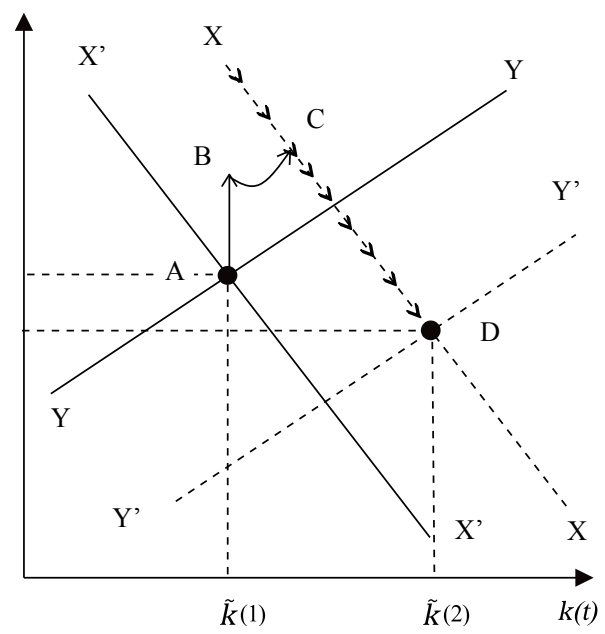

Source: Prepared by the authors. 
In the short run, right after the announcement of a cut in $\alpha$, the marginal utility of wealth $\lambda(0)$ jumps directly to the stable arm (point $B$ in the straight line $X^{\prime} X^{\prime}$ ). This results in a decline in private wealth, causing a reduction in private consumption and an increase in labour supply. The increase in labour supply leads to an improvement in the marginal productivity of capital, which results in an increase in the short-term interest rate.

At the same time, the marginal productivity of capital increases more than that of the steady-state equilibrium. According to the equilibrium equation (7) this makes $\dot{\lambda}(t)<0$, implying that the marginal utility of wealth should decrease, while private consumption should grow. However, note that the time spent by both to reach a new steady-state equilibrium according to equation (14) increases as the primary surplus as a percentage of GDP rises (higher for $\beta$ ).

We can still note that the fall in initial private consumption levels improves savings, thus resulting in an accumulation of physical capital. In this context, the economy follows a trajectory from B to C. Private consumption, capital stock (investment), output and labour supply are higher in this new equilibrium than in the initial equilibrium.

In the case of an anticipated shock, when the government announces a reduction of $\alpha$ at a future date $T$, provided agents discount the change in the future, the jump in the marginal utility of wealth should be lower. In the annex, we show that the more distant the time of the policy change, the lower the $\lambda(t)$ jump. Therefore, $\lambda(t)$ jumps from A to B, as shown in figure $2 \mathrm{~B}$.

As in the unanticipated case, the capital stock in the new equilibrium shall be higher and the marginal utility of wealth lower, and consequently, private consumption shall grow. The main difference is the lower $\lambda(0)$ jump, which results in a smaller decline in private wealth. Therefore, labour supply increases while output grows and private consumption falls, but to a lesser extent.

In the short term the adverse effects of an anticipated policy are more limited than in the case of the same policy announced immediately. For example, the reduction in consumption in the first case is more limited than in the second. It therefore appears advisable for the government to adopt anticipated policies in the short term.

At the same time, as the labour supply increases, the marginal productivity of capital improves, causing short-term interest rates to rise. This also makes $\dot{\lambda}(t)>0$, in line with the equilibrium equation (7). This result, combined with the savings increase, causes $\lambda(t)$ and $k(t)$ to follow the unstable trajectory $\mathrm{BC}$ until they reach the stable arm $X^{\prime} X^{\prime}$. In fact, the change in $\alpha$ takes place in period $T$. The displacement of $\lambda(t)$ and $k(t)$ in this trajectory is conveyed in figure $2 \mathrm{~A}$.

As from this point, $\lambda(t)$ and $k(t)$ follow their trajectories on the stable arm until they reach the new long-run equilibrium, represented by point $\mathrm{D}$ in figure 2B. Private consumption, capital stock (investment) and output are also higher compared to the initial equilibrium.

Note also that the effects of an increase in government consumption spending on private consumption, investment and output are not symmetrical to those in the case of an increase in infrastructure spending, regardless of the announcement being anticipated or not.

\section{Permanent fiscal shock in $\beta$}

In this case, the government announces in the present (unanticipated fiscal policy) that it will increase the primary surplus as a percentage of GDP (increase in $\beta$ ). According to the signs of $\partial \widetilde{k} / \partial \beta<0$ and $\partial \widetilde{\lambda} / \partial \beta>0$, in the long-run equilibrium scenario the capital stock shall be lower than the marginal utility of wealth compared to the initial equilibrium. In fact, in figure $2 \mathrm{C}$, the increase in $\beta$ displaces the stable arm from $X X$ to $X^{\prime} X^{\prime}$ and the unstable arm from $Y Y$ to $Y^{\prime} Y$ '. The new steady-state equilibrium (long-run) is represented by point $C$. 
Figure 2

C. Unanticipated shock

$\lambda(t)$

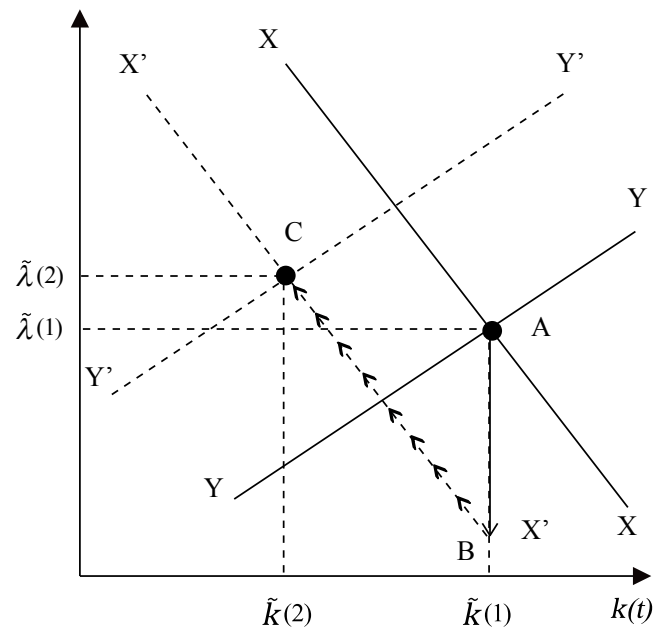

D. Anticipated shock

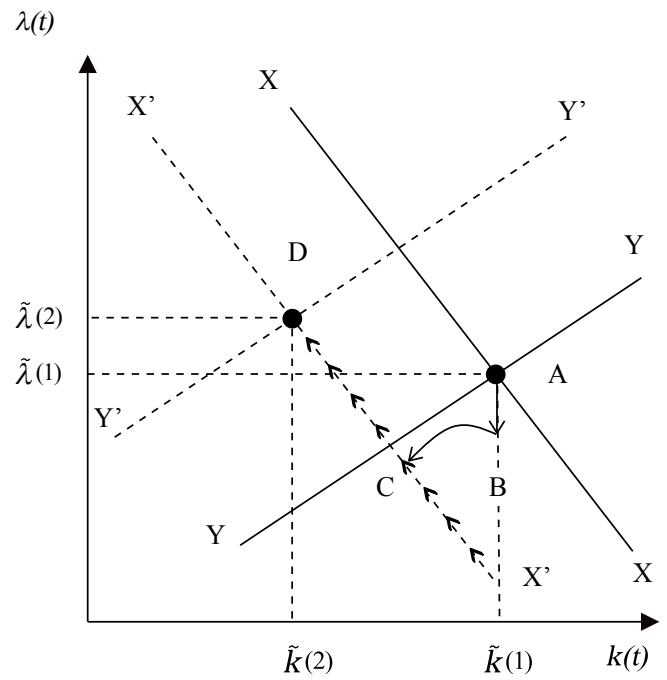

Source: Prepared by the authors.

Following the announcement, the marginal utility of wealth $\lambda(0)$ immediately jumps from an initial equilibrium $A$ to reach the stable arm $X^{\prime} X^{\prime}$ at point $B$. The growth in private wealth owing to the decline in $\lambda(t)$ is short-term and results in a reduction in labour supply, which in turn leads to a decrease in the marginal productivity of capital and therefore, in short-term interest rates.

At the same time, the decrease in the marginal productivity of capital below the long-run equilibrium causes the marginal utility of wealth to grow again in order to maintain the equilibrium equation (7). This is followed by a fall in private consumption. Meanwhile, the initial improvement in consumption (savings decrease) generates a reduction in physical capital. In this context, the trajectories of $\lambda(t)$ and $k(t)$ move from point $B$ to a new long-run equilibrium represented by point $C$. In this new long-run equilibrium, private consumption, physical capital stock and output are lower and labour supply is higher compared to the initial equilibrium.

The effects of the announcement of a policy change that will occur at a future date $T$ (anticipated fiscal policy) are similar to those in the case of an unanticipated announcement. The main difference is that the jump in $\lambda(0)$ is smaller because agents anticipate that policy changes will only occur at a future time $T$.

In the short term, anticipated policies produce fewer adverse effects than unanticipated policies. For example, the decline in private consumption when an anticipated policy is applied is smaller than when an unanticipated policy is implemented. This result indicates that policies anticipated in the short term are preferable to unanticipated policies.

According to figure 2D, in the case of an anticipated shock, the marginal utility of wealth falls from $A$ to $B$, which means that private wealth should grow. The higher the T value, the lower $\lambda(0)$ the jump. In the short run, the marginal productivity of capital diminishes, implying a fall in short-term interest rates but to a lesser extent. Considering the equilibrium equation (7) we can conclude that the fall in the marginal productivity of capital implies that $\dot{\lambda}(t)>0$. Consequently, private consumption must decrease in order to maintain the marginal utility of wealth equilibrium. At the same time, growth in the initial consumption generates a reduction in savings, thus discouraging investments. Therefore, the economy follows a trajectory from $\mathrm{C}$ to $\mathrm{D}$, when it reaches a new long-term equilibrium. 
In this new equilibrium, private consumption, capital stock, output and labour supply are similar to the levels seen in unanticipated cases when comparing the initial and final equilibria. The effects of a cut in the primary surplus ( $\beta$ fall) are clearly symmetrical to the effects of a primary surplus increase.

To sum up, in terms of generating economic growth, the fiscal policy of infrastructure spending is more effective than the policy of maintaining a primary surplus as a proportion of GDP. Therefore, this infrastructure spending policy, combined with the constant real expenditure policy, are more effective in promoting economic growth and reducing the fiscal deficit. In this case, the levels of output and private investment in the final long-run equilibrium are greater than in the initial equilibrium, regardless of whether the shocks are anticipated or unanticipated. On the other hand, in the case of the primary surplus policy, the levels of output and private investment in the final long-run equilibrium are lower than in the initial equilibrium, regardless of the type of shock.

\section{Term structure of interest rates}

We assume that perpetual bonds pay a long-term interest rate through a single periodic coupon with the value set in a given monetary unit. If $P(t)$ is the bond price and $R(t)$ is its internal return rate, we have that $R(t)=\frac{1}{P(t)}$.

In efficient and risk-free markets, through arbitrage, the short-term rate $r(t)$ shall be equal to the long-term rate plus capital $\frac{\dot{P}(t)}{P(t)}$. Therefore, $r(t)=\frac{1}{P(t)}+\frac{\dot{P}(t)}{P(t)}$, which originates the differential
equation $\dot{P}(t)-r P(t)=-1$.

The solution to this equation for $P(t)$ looking into the future, as shown in the annex, results in the following expression: $P(t)=\int_{t}^{\infty} e_{t}^{-\int_{t}^{s} r(w) d w} d s$. Provided that $R(t)=\frac{1}{P(t)}$, the long-term interest rate may be defined as $R(t)=\frac{t}{\int_{t}^{\infty} e_{t}^{-\int_{t}^{s} r(w) d w} d s}$, defining $P(t, s)=e_{t}^{-\int_{t}^{s} r(w) d w}$ as the price of a zero-coupon bond in a period $t$ that matures on date $s$, so we have that $P(t, s)=e_{t}^{-\int_{t}^{s} r(w) d w}$.

However, according to our hypothesis, the long-term bond has a unitary face value, which shall have to be equal to the sum of short-term rates considering the price for a period $t$ of a zero-coupon bond that matures on date $s$. In other words, $\int_{t}^{\infty} r(s) P(t, s) d s=1$.

Consequently, the long-term interest rate $R(t)$ may be expressed as:

$$
R(t)=\frac{\int_{t}^{\infty} r(s) P(t, s) d s}{\int_{t}^{\infty} P(t, s) d s}
$$

In other words, the long-term interest rate is a weighted average of short-term interest rates perfectly foreseen for the future.

From equilibrium conditions (7) and (8) we obtain that $r=(1-\beta) f_{k}(K, l(\lambda, K)) h[(1-\alpha) \bar{g}]$. Linearizing this expression around the steady-state equilibrium, we find that its trajectory follows 
the expression: $r(t)=\tilde{r}+(1-\beta) w_{21}(k(t)-\tilde{k})+(1-\beta) w_{22}(\lambda(t)-\tilde{\lambda})$, where $\tilde{r}=\rho$. Therefore, the short-term interest rate dynamic is obtained by differentiating the expression $r(t)$ above. ${ }^{5}$

Consequently,

$$
\dot{r}(t)=(1-\beta) w_{21} \dot{k}(t)+(1-\beta) w_{22} \dot{\lambda}(t)
$$

As $R(t)$ is a weighted average, the short-term interest rate is perfectly foreseen for the future. According to (expression 15), the dynamics are established from the analysis of (16).

\section{Permanent shocks of $\alpha$ on short- and long-term interest rates}

Initially, we consider the case of an unanticipated fiscal policy in which the fiscal authority immediately announces an increase in permanent infrastructure spending (fall in $\alpha$ ). According to the analysis developed in subsection III.1, $\lambda(t)$ immediately jumps to the stable arm $X^{\prime} X^{\prime}$. This growth in $\lambda(t)$ causes an increase in the marginal productivity of capital that, at the same time, increases short-term interest rates. Therefore, the short-term interest rate also jumps, followed by a gradual decrease through time, as shown in figure 3A.

Figure 3
A. Unanticipated shock
B. Anticipated shock
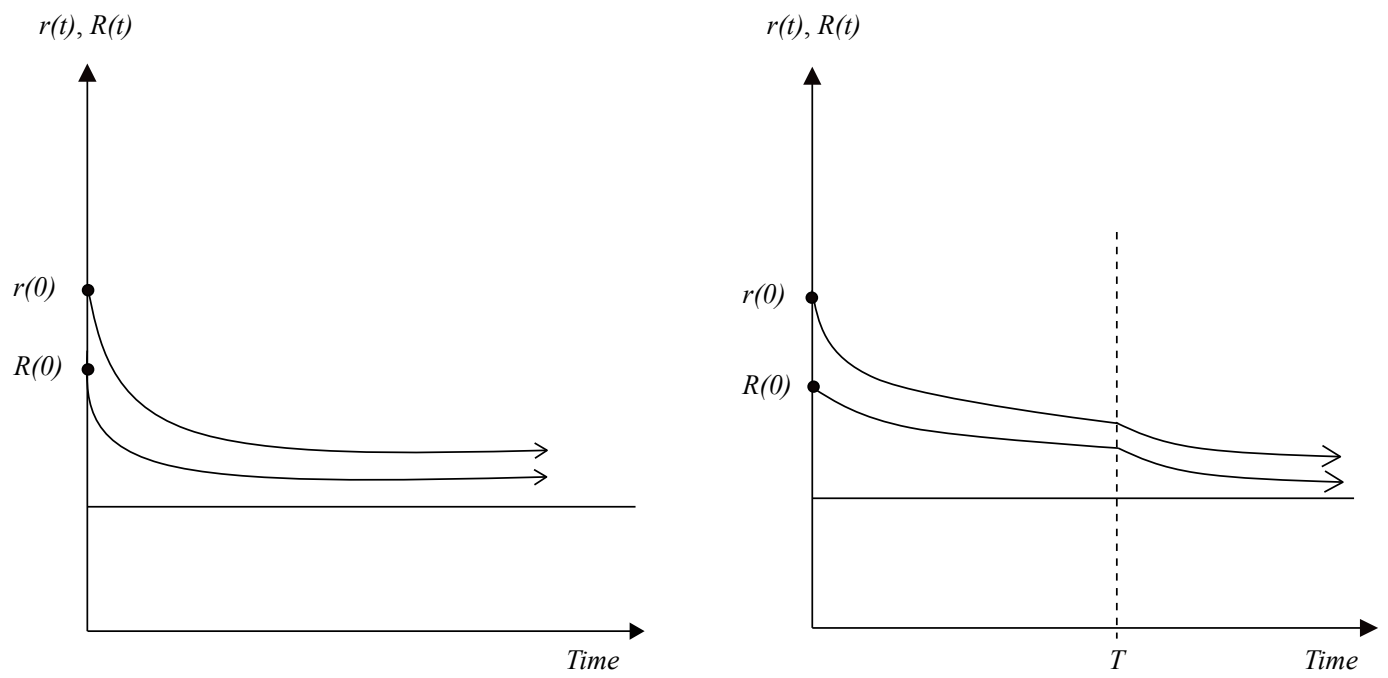

Source: Prepared by the authors.

Since the dynamics of the rate $r(t)$ are governed by equation (16), and as after the jump of $\lambda(t)$, $k(t)$ follows a growing trajectory $(\dot{k}(t)>0)$ and $\lambda(t)$ follows a decreasing trajectory $\dot{\lambda}(t)<0)$, the short-term interest rate shall decrease through time until it reaches its steady-state equilibrium $\rho$.

The long-term interest rate is expressed as a weighted average of the short-term interest rates perfectly foreseen for the future according to expression (15). The long-term interest rate also jumps from its initial equilibrium $\rho$ to then decrease through time, always lagging the trajectory of $r(t)$, until converging again to its initial equilibrium level. As shown in expression (16), short- and long-term interest rate convergences slow down as the primary surplus as a percentage of GDP rises (increase in $\beta$ ).

\footnotetext{
5 Seeking the dynamics of $R(t)$, provided that $\dot{R}=R\left[R-(1-\beta) f_{k}(K, l(\lambda, K))\right]$, and linearizing this expression with the steady-state equilibrium, we obtain that: $\dot{R}(t)=\rho\left[(R(t)-\tilde{R})-(1-\beta) w_{21}(k(t)-\tilde{k})-(1-\beta) w_{22}(\lambda(t)-\tilde{\lambda})\right]$ in which $\dot{R}=\rho$.
} 
In the case of an announcement of the increase in infrastructure expenses at a future date $T$ (anticipated fiscal policy) the convergence trajectories of interest rates are similar to those seen in the previous case but with subtle differences. These trajectories are illustrated in figure 3B. First, their initial jumps are more limited, as agents anticipate that the changes shall only take place at a future time $T$. Second, after the jump of $\lambda(t)$ to $\mathrm{B}$ in figure $2 \mathrm{~B}, k(t)$ and $\lambda(t)$ follow a decreasing unstable trajectory to the stable arm $X^{\prime} X^{\prime}$, when the policy change occurs at time $T$. According to expression (16), in this same period of time, the interest rate $r(t)$ decreases, albeit to a lesser extent $\lambda(t)$ as shown in figure 3B. On the basis of time $T$, as $k(t)$ grows and $\lambda(t)$ decreases, the short-term interest rate converges more rapidly towards its initial equilibrium than in its previous trajectory.

\section{Permanent $\beta$ shocks on short- and long-term interest rates}

Initially, we considered the case in which the government announces an immediate increase in the primary surplus as a percentage of GDP (unanticipated fiscal policy). As seen before, this implies an increase in the fiscal policy parameter $\beta$.

In figure $2 \mathrm{C}$ of subsection III.2, an increase in $\beta$ causes a small jump in the short-term interest rate in the moment the change of policy is announced owing to a fall in the marginal utility of wealth. After the initial fall of $\lambda(t)$, the capital stock $k(t)$ starts to decrease and $\lambda(t)$ grows. According to the equation dynamics in (16), the short-term rate begins to rise through time until it returns to its long-term equilibrium $\rho$, as shown in figure 3C.

Figure 3

\section{Unanticipated shock}

$$
r(t), R(t)
$$

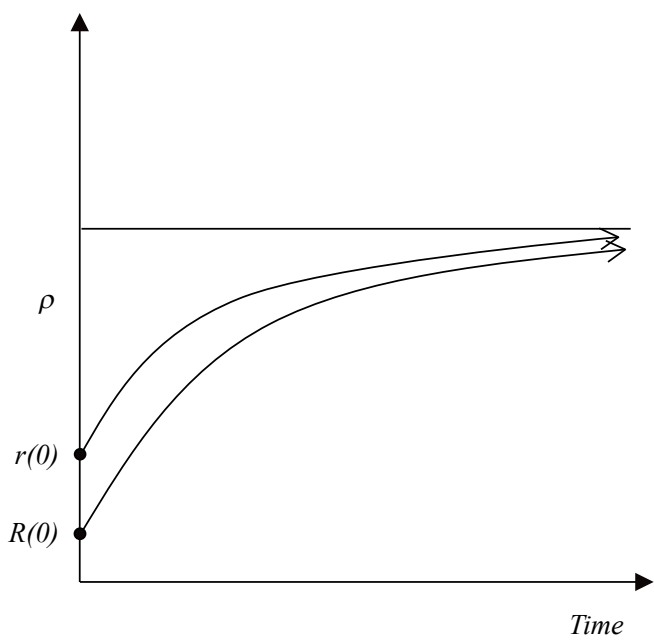

$r(t), R(t)$

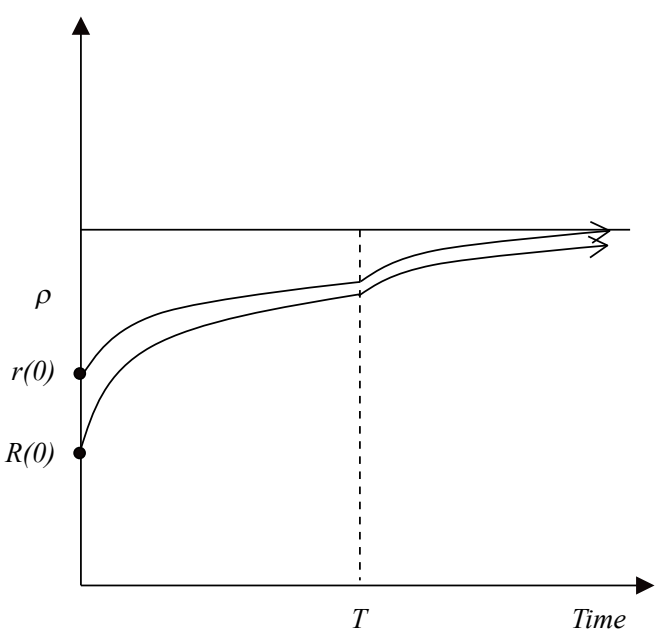

Source: Prepared by the authors.

Since the long-term interest rate is a weighted average of short-term interest rates perfectly foreseen for the future, it also suffers a larger initial fall than in the case of short-term rates. After this initial fall, it reflects a growing trajectory, but always below the short-term rate, until it reaches its initial equilibrium level $\rho$. Figure $3 \mathrm{C}$ illustrates this convergence very clearly.

Once again, it is important to highlight that the increase in $\beta$ intensity delays the convergence of both interest rates further. 
When primary surplus growth occurs at a future date $T$ (anticipated fiscal policy), the movements of the short- and long-term interest rates are not very different. The same is true in the case of unanticipated fiscal policy: both interest rates decline but to a lesser extent. Ultimately, agents discount the fact that there will only be a policy change at a future date (see figure 3D). As from these jumps, both interest rates start to grow through time, but the long-term rate is always lower than the short-term rate. Figure $2 \mathrm{D}$ shows that after the initial $\lambda(t)$ jump, the capital stock and the marginal utility of wealth follow unstable trajectories (from $B$ to $C$ ) until $C$ is reached, when there is in fact growth in the primary surplus. This happens in a period of time T. In these trajectories, as $k(t)$ and $\lambda(t)$ decrease through time, we can conclude from equation (16) that the short-term interest rate must increase although the decline in $\lambda(t)$ limits growth.

As from point $\mathrm{C}, k(t)$ continues its declining trajectory while $\lambda(t)$ starts to increase. The result is that the short-term interest rate, after the period of time T, continues to rise more rapidly than in the previous period. The long-term interest rate reflects the same movement, but its trajectory towards initial equilibrium always remains lower than that of the short-term interest rate. Ultimately, it is simply a weighted average of short-term rates perfectly foreseen by agents.

In this case, the intensity of the fiscal policy parameter $\beta$ slows down the convergence of both interest rates towards their final equilibrium.

\section{Fiscal policy and welfare}

The analysis of the effects of changes in fiscal policy parameters on welfare considers the total utility discounted from agents. For this purpose, we use the instant utility stable trajectory linearized around its steady state. ${ }^{6}$ According to Fisher and Turnovsky (1995) and Turnovsky (1995) the utility of agents $U\left(c(t), l(t), g_{c}(t)\right)$ may be broken down as: $U(t) \cong \widetilde{U}+(U(0)-\widetilde{U}) e^{\mu_{1} t}$, in which, for simplification purposes, we adopt: $U(t)=U\left(c(t), l(t), g_{c}(t)\right)$.

Denoting the total discounted utility that measures agent welfare by $W, W=\int_{0}^{\infty}\left[\widetilde{U}+(U(0)-\widetilde{U}) e^{\mu_{1} t}\right] e^{-\rho t} d t$ which implies that: $W=\frac{\widetilde{U}}{\rho}+\frac{(U(0)-\widetilde{U})}{\rho-\mu_{1}}$.

In the expression above, the term $\widetilde{U} / \rho$ represents the instant welfare discounted by the intertemporal rate $\rho$. This term expresses the resulting welfare level if the long-term equilibrium is reached immediately. The term $\frac{(U(0)-\widetilde{U})}{\rho-\mu_{1}}$ represents the adjustment until long-term equilibrium is achieved, as in an economy with capital accumulation, the steady state is gradually reached. ${ }^{7}$

The main goal of this section is to find a budget policy that maximizes social well-being. Specifically, we intend to obtain expressions for $\widehat{\alpha}$ and $\widehat{\beta}$, such that:

$$
(\widehat{\alpha}, \widehat{\beta})=\underset{\alpha, \beta \in[0,1]}{\operatorname{argmax}} W
$$

Unfortunately, it is not possible to obtain a general solution for (17) once the dependency of $U(0)$ and $\widetilde{U}$ in parameters $\alpha$ and $\beta$ is implicitly given by the representative agent utility function and the production technology. Therefore, in search of a better solution to the problem, we shall highlight some specifications:

\footnotetext{
6 This paper does not analyse the optimality of the policies presented. See Chari and Kehoe (1999) for a detailed discussion of the optimality of fiscal and monetary policies.

7 See Stockman (2001) for a discrete-time version of that approach.
} 
Initially, problem (17) may be replaced by the equivalent problem:

$$
(\widehat{\alpha}, \widehat{\beta})=\underset{\alpha, \beta \in[0,1]}{\operatorname{argmax}} \bar{W}
$$

where $\bar{W}=\rho W$, such that $\bar{W}=\tau U(0)+(1-\tau) \widetilde{U}$ with $\tau=\rho /\left(\rho+\left|\mu_{1}\right|\right)$. It is assumed that $\tau$ is independent of $\alpha$ and $\beta$.

In addition to the assumptions above, functional forms for the utility of a representative consumer and for production technology shall be adopted. According to Christiano, Eichenbaum and Rebelo (2011) it is assumed that the (instant) utility function of a representative consumer is:

$$
U(c, l, \alpha \bar{g})=\frac{\left(c^{\gamma}(1-l)^{1-\gamma}\right)^{1-\sigma}-1}{1-\sigma}+\varphi \ln \alpha \bar{g} \text { se } \sigma \neq 1
$$

so that all parameters of this utility function are non-negative with $0<\gamma<1$.

The production function, at the same time, follows the suggestion of Barro (1990) on productive public expenditure, such that:

$$
F(k, l,(1-\alpha) \bar{g})=A k^{\delta} l^{1-\delta}((1-\alpha) \bar{g})^{\eta}
$$

where all parameters of the specified function above are positive and $0<\delta<1$. Observe that parameter $\eta$ measures product elasticity with regard to infrastructure expenditure.

Finally, it is assumed that the taxation scheme in $t=0$ and that in the steady state they shall be treated as parameters. This means that if we consider $y(t)$ as the per capita output of the economy, for each austerity policy $\beta$, we will have that: $\beta y(0)=T(0)-\bar{g}=s_{0}$ and $\beta \tilde{y}=\widetilde{T}-\bar{g}=\tilde{s}$.

Hence, the assumption above means that in problem (18), $s_{0}$ and $\tilde{s}$ shall be treated as parameters.

With the above specifications, it is possible to obtain explicit solutions for the endogenous variables of the model using the initial data, as well as for the steady state. According to proposition 1 in the annex, solutions for labour supply and private consumption for $t=0$ are respectively: (a) $l(0)=\left[\frac{s_{0}}{\beta A k_{0}^{\delta}((1-\alpha) \bar{g})^{\eta}}\right]^{\frac{1}{1-\delta}}$ and (b) $c(0)=\frac{\gamma(1-\delta)_{s_{0}}(1-l(0))}{\beta(1-\gamma) l(0)}$.

In the steady state, solutions for consumption, labour supply and capital stock are equal to:

(c) $\tilde{l}=\frac{(1-\gamma)(\tilde{s}-\beta \bar{g})}{(1-\gamma)(\tilde{s}-\beta \bar{g})+\gamma(1-\delta)(1-\beta) \tilde{s}}$, (d) $\tilde{c}=\frac{\tilde{s}-\beta \bar{g}}{\beta}$ and (e) $\tilde{k}=\frac{(1-\beta) \tilde{\delta} \tilde{s}}{\rho \beta}$.

Replacing these solutions (a, b, c, d and e) in (19), after some algebraic manipulations, we obtain the following expressions for $U(0)$ and $\widetilde{U}$ :

$$
\begin{aligned}
& U(0)=\left[\frac{\gamma(1-\delta)}{\beta(1-\gamma)}\right] \frac{s^{\frac{-\gamma \delta(1-\delta)}{1-\delta}}\left[\phi(\alpha)^{\frac{1}{1-\delta}}-s 0^{\frac{1}{1-\delta}}\right]^{1-\delta}}{\phi(\alpha)^{\frac{(1-\gamma)(1-\sigma)}{1-\sigma}}}+\varphi \ln \alpha \bar{g}-\frac{1}{1-\sigma} \\
& \widetilde{U}=\frac{(1-\gamma)^{(1-\gamma)(1-\sigma)}(\tilde{s}-\beta \bar{g})^{(1-\sigma)}}{\beta^{\gamma(1-\delta)}(1-\delta)[(1-\gamma)(\tilde{s}-\beta \bar{g})+\gamma(1-\delta)(1-\beta) \bar{s}]}+\varphi \ln \alpha \bar{g}-\frac{1}{1-\sigma}
\end{aligned}
$$

where $\phi(\alpha)=\beta A k_{0}^{\delta}((1-\alpha) \bar{g})^{\eta}$.

Before investigating first-order conditions for this problem (18), it is important to verify whether there are corner solutions, as they must be restricted to the unitary interval. Initially, solutions $\beta=0$ and 
$\alpha=1$ may be ruled out as the objective function is discontinued, thus making the use of first-order conditions impossible. We can also note that the objective function depends on $\alpha$, which tends to be more finite when $\alpha$ is close to zero. Therefore, the solution $\alpha=0$ cannot be optimal.

The solution $\beta=1$ cannot be ruled out immediately. However, if this was the case, the economy would develop a trajectory in which assets would be destroyed, as there would be no accumulation. Consequently, the problem shall be treated as a maximization problem without restriction and first-order conditions shall be analysed if $\beta=1$ satisfies these conditions.

Using the equations (20) and (21), the first-order conditions in (18) for $\alpha$ and $\beta$ are respectively given by: 8

$$
\left[\frac{\tau \eta(1-\sigma)}{1-\sigma}\right]\left[\frac{\gamma(1-\delta) s_{0}}{\widehat{\beta}(1-\gamma)}\right]^{\gamma(1-\sigma)} \frac{\left[\phi(\widehat{\alpha})^{\frac{1}{1-\sigma}}-s_{0}^{\frac{1}{1-\delta}}\right]^{-\sigma}\left[\gamma \phi(\widehat{\alpha})^{\frac{1}{1-\delta}}+(1-\gamma) s_{0}^{\frac{1}{1-\delta}}\right]}{\phi(\widehat{\alpha})^{\frac{(1-\gamma)(1-\sigma)}{1-\delta}}}=\frac{1-\widehat{\alpha}}{\widehat{\alpha}}
$$

and

$-\tau\left[\frac{\gamma(1-\delta)}{(1-\gamma)}\right] \gamma \hat{\beta}^{\gamma(1+\gamma(1-\sigma)]} s_{0} \cdot \frac{\delta \gamma(1-\sigma)}{1-\delta} \frac{\left[\phi(\widehat{\alpha})^{\frac{1}{1-\delta}}-s_{0}^{\frac{1}{1-\delta}}\right]^{1-\sigma}}{\varphi(\widehat{\alpha})^{\frac{(1-\gamma)(1-\sigma)}{1-\delta}}}+(1-\tau) \frac{(1-\gamma)^{(1-\gamma)(1-\sigma)} \widehat{\beta}^{-\gamma(1-\sigma)}(\tilde{s}-\widehat{\beta} \bar{g})^{-\sigma}}{(1-\sigma)[(1-\sigma)(\tilde{s}-\widehat{\beta} \bar{g})+\delta \sigma(1-\widehat{\beta}) \tilde{s}]^{(1-\gamma)(1-\sigma)}} x$

$$
x\left\{-\gamma(1-\sigma) \widehat{\beta}^{-1}(\tilde{s}-\widehat{\beta} \bar{g})+\frac{[(1-\gamma) \delta \sigma \tilde{s}-\gamma(1-\sigma) \bar{g}](\tilde{s}-\widehat{\beta} \bar{g})-\delta \sigma(1-\widehat{\beta}) \bar{g}}{(1-\sigma)(\tilde{s}-\widehat{\beta} \bar{g})+\delta \sigma(1-\widehat{\beta}) \tilde{s}}\right\}=0
$$

Observe that an explicit solution for (22) and (23) is possible only in very special cases (some of which shall be analysed later on). However, it is possible to reach some qualitative conclusions on optimal austerity rules and budget composition without the need for explicit solutions.

Using equation (22), proposition 2 in the annex affirms that if $\eta>\left[\left(\frac{1-\gamma}{\gamma}\right)^{\gamma(1-\sigma)}\right] / \tau(1-\sigma)$, then any valid solution for $\alpha$ must be such that $\hat{\alpha}<0.5$ This leads to the following conclusion: if the output elasticity with regard to infrastructure expenditure is high enough and if the employment volume on the initial date represents more than half of the available workforce, the socially optimal solution prescribes that the largest portion of public budget should be allocated to investments (infrastructure expenditure). In order to have an idea of the magnitude of $\eta$ necessary to validate proposition 2, let us consider a numeric example. Suppose that leisure and consumption are equally weighted in the utility of the representative agent and that the elasticity of intertemporal substitution is equal to 2 . In this case, we have that $\gamma=0.5$ and $\sigma=0$, such that the condition for output elasticity with regard to public spending on infrastructure is $\eta>1 / \tau$. This implies that the lesser the importance of the utility today in a long-term relation, the higher the $\eta$ level necessary to have as a social optimum that $\hat{\alpha}<0.5$.

The result above deserves some consideration. The inverse relationship between output elasticity and short-term welfare means that first and foremost, $\eta>1$, which means that in order to grant an optimal social condition, we need to allocate the largest portion of the budget to investment. The economic output must be elastic with regard to investment, because as specified by the Cobb-Douglas production function, both private and public capital represent some level of substitution, ${ }^{9}$ so that the higher the $\eta$ value, the lower the substitution. Consequently, in the composition of economic output, public and private capital shall complement each other.

\footnotetext{
8 The details of the process are available in the annex.

9 Specifically, the marginal rate of technical substitution between private and public capital is given by $\frac{\delta(1-\alpha) \bar{g}}{\eta k}$.
} 
The arguments above add to the analysis of fiscal shocks to long-term equilibrium. As seen in section III, an increase in the percentage of spending allocated to infrastructure always raises capital stock in a steady state. Therefore, considering long-term effects, the higher the value of $\eta$, the stronger the impact on output resulting from an increase in infrastructure expenditure, as both private and public capital shall grow complementarily.

Finally, a lower $\tau$ value means a higher $\eta$, which implies that the long-term importance in the composition of welfare shall increase, thus reinforcing the arguments in favour of private and public capital complementing each other more.

Note that the result $\hat{\alpha}<0.5$ is independent of the value of $\beta$ in the socially optimal situation. Hence, in this case the expression $\widetilde{\beta}=\frac{\widetilde{T}-\widetilde{g}}{\widetilde{y}}=\frac{\tilde{s}}{\widetilde{y}}$ is sufficient to determine the optimal fiscal austerity rule, where $\tilde{y}$ is the output in the steady state that is obtained by applying proposition 1 .

Note that although the solution proposed for $\widetilde{\beta}$ is implicit, its scale clearly depends on the size of the primary surplus (tax burden) desired by the fiscal authority and the size of the output in long-term equilibrium. Specifically, through an implicit differentiation, it may be proved that the sign of $d \widetilde{\beta} / d s$ depends on $1-\varepsilon_{y, s}$, where $\varepsilon_{y, s}$ is the output elasticity in relation to the magnitude of the primary surplus determined by the fiscal authority (both in long-term conditions). As this elasticity is always positive (by definition) the sign of $d \widetilde{\beta} / d s$ depends on the magnitude of $\varepsilon_{y, s}$.

More specifically, if the output is inelastic with regard to the primary surplus, then the larger the primary surplus, the larger the magnitude of $\widehat{\beta}$. This is an intuitive result and at first sight, is the only possible one. However, the model creates a possibility for an increase in $s$ that may be accompanied by a reduction in $\beta$. To that end, it is enough for economic output to be elastic in relation to the primary surplus, which means that if $\varepsilon_{y, s}>1$, the sign of the $d \widetilde{\beta} / d s$ derivative is negative.

What is the reason for this result? Initially, it seems reasonable to assume that the magnitude of $\varepsilon_{y, s}$ depends on the influence of the government on the economy (measured by the ratio $\bar{g} / y$ ) as follows: the bigger the influence of the government on the economy, the more intense the impact of fiscal results on output. That said, it may be theorized that in economies in which $\bar{g} / y$ is large enough, we have that $\varepsilon_{y, s}>1$. Naturally, this conjecture has not been proven through a general proposition or empirical regularity. In any case, both analyses are beyond the scope of this research. ${ }^{10}$

\section{Concluding remarks}

In the case of unanticipated fiscal policy, the announcement of an immediate and permanent increase in infrastructure expenditure causes a short-term fall (jump) in private wealth, thus resulting in a decline in consumption and growth in the labour supply. From that point onward, a dynamic of initial equilibrium is initiated for a new long-run equilibrium (steady-state equilibrium). As in the initial moment, there is a fall in private consumption and the capital stock starts to increase towards a new long-run equilibrium. Simultaneously, the marginal utility of wealth starts declining after its initial growth. However, the time that the marginal utility of wealth, private consumption and labour supply take to reach a new steady-state equilibrium is longer as the primary surplus grows as a percentage of GDP.

In the final long-run equilibrium, private consumption, capital stock (investment), output and labour supply are higher than in the initial equilibrium state.

\footnotetext{
10 The point may be introduced less dramatically if the relationship between the magnitudes of $\varepsilon_{y, s}$ and $\bar{g} / y$ is assumed to be probabilistic. Specifically, by using notation $G=\bar{g} / y$, it may be accepted that $\operatorname{Pr}\left[\varepsilon_{y, s}>\frac{1}{G}\right]$ is a growing $G$ function.
} 
In the case of anticipated fiscal policy, the effects of the increase in infrastructure expenditure on output, consumption and capital stock are similar to those seen in the case of unanticipated fiscal policy. The main difference is the more limited jump in the marginal utility of wealth in the short term.

We should also note that the effects of an increase in government consumption spending on output, private consumption, investment and labour supply are symmetrical to those in the case of an increase in infrastructure expenditure, regardless of whether the announcement is anticipated or unanticipated.

In the case of unanticipated fiscal policy related to the increase in the short-term primary surplus, consumption improves and labour supply decreases, resulting in a decline in the marginal productivity of labour. In the long run, output, private consumption and capital stock are lower and the labour supply grows in comparison to the initial equilibrium.

In summary, we conclude that in terms of generating economic growth, the fiscal policy of increasing government spending on infrastructure is more effective than the policy of maintaining a primary surplus as a proportion of GDP. Therefore, this infrastructure spending policy combined with the constant real spending policy that tackles the fiscal deficit are more effective in promoting economic growth.

As for the term structure of interest rates, the unanticipated fiscal policy of increasing infrastructure expenses causes an immediate jump in the short-term interest rate, followed by a decreasing trajectory towards long-term equilibrium. Since the long-term interest rate is a weighted average of short-term rates perfectly foreseen for the future, it also jumps, but to a lesser extent, before quickly converging to steady-state equilibrium. However, the higher the primary surplus goal, the longer both interest rates shall take to reach their new equilibria.

In the case of anticipated fiscal policy, in which the increase in the primary surplus shall take place at a future date, short- and long-run movements are similar to the previously described situation. This is also the case with unanticipated policy, as both interest rates also fall, but do so less dramatically. In the end, agents discount that there will only be a policy change in the future. After falling, both interest rates start to rise again through time, but with the trajectory of the long-term rate always lagging that of the short-term rate. From the moment the policy change takes place, both rates begin rising more rapidly compared to the previous period.

In this case, the magnitude of the primary surplus slows down the convergence of both interest rates towards their final long-term equilibria.

Lastly, fiscal and budgetary policy outcomes that maximize social well-being suggest that if output is sufficiently sensitive to infrastructure expenditure or if the short run is not very relevant in the total discounted utility considered, the largest portion of public resources must be allocated to investment spending, provided the total of employed workers is higher than $50 \%$ of the available workforce. The percentage of GDP allocated to the primary surplus depends on per capita income elasticity with regard to the economy's fiscal performance. Specifically, if per capita income is elastic with regard to the primary surplus, even if the fiscal authority decides on an absolute increase in this surplus, the allocated percentage of GDP may end up being lower. 


\section{Bibliography}

Agénor, P. (2005), "Fiscal adjustment and labor market dynamics in an open economy", Journal of Development Economics, vol. 76, No. 1, February.

Aschauer, D. (1990), "Why is infrastructure important?", Is There a Shortfall in Public Capital Investment?, A. Munnell (ed.), Conference Series, No. 34, Boston, Federal Reserve Bank of Boston. (1989), "Is public expenditure productive?", Journal of Monetary Economics, vol. 23, No. 2, March. (1988), "The equilibrium approach to fiscal policy", Journal of Money, Credit and Banking, vol. 20, No. 1, February.

Barro, R. (1990), "Government spending in a simple model of endogenous growth", Journal of Political Economy, vol. 98, No. 5.

Baxter, M. and R. King (1993), "Fiscal policy in general equilibrium", The American Economic Review, vol. 83, No. 3, June.

Blanchard, O. (1981), "Output, the stock market, and interest rates", The American Economic Review, vol. 71, No. 1, March.

Chari, V. and P. Kehoe (1999), "Optimal fiscal and monetary policy", NBER Working Paper, No. 6891, Cambridge, National Bureau of Economic Research (NBER), January.

Christiano, L., M. Eichenbaum and S. Rebelo (2011), "When is the government spending multiplier large?", Journal of Political Economy, vol. 119, No. 1, February.

Cox, J., J. Ingersoll and S. Ross (1985), "A theory of the term structure of interest rates", Econometrica, vol. 53, No. 2, March.

De la Fuente, A. (2000), Mathematical Methods and Models for Economists, New York, Cambridge University Press.

Fisher, W. and S. Turnovsky (1995), "The composition of government expenditure and its consequences for macroeconomic performance", Journal of Economic Dynamics and Control, vol. 19, No. 4, May. (1992), "Fiscal policy and the term structure of interest rates: an intertemporal optimizing analysis", Journal of Money, Credit and Banking, vol. 24, No. 1, February.

Hirsch, M. and S. Smale (1974), Differential Equations, Dynamical Systems, and Linear Algebra, New York, Academic Press.

IPEA (Institute for Applied Economic Research) (2016), "Ipeadata” [online] http://www.ipeadata.gov.br.

Marinho, E. and M. Benegas (2006), "Ajuste fiscal no Brasil: por que adotar o regime de superávit primário ou o de déficit nominal zero?" [online] http://www.tesouro.fazenda.gov.br/premio/Premio_TN/Xlpremio/ divida/1afdpXIPTN/1premio_afdp.pdf.

McCafferty, S. (1986), "Aggregate demand and interest rates: a macroeconomic approach to the term structure", Economic Inquiry, vol. 24, No. 4.

Stockman, D. (2001), "Balanced-budget rules: welfare loss and optimal policies", Review of Economic Dynamics, vol. 4, No. 2, April.

Turnovsky, S. (1995), Methods of Macroeconomic Dynamics, Cambridge, MIT Press.

Turnovsky, S. and M. Miller (1984), "The effects of government expenditure on the term structure of interest rates", Journal of Money, Credit and Banking, vol. 16, No. 1, February.

Woodford, M. (1996), "Control of the public debt: a requirement for price stability?", NBER Working Paper, No. 5684, Cambridge, National Bureau of Economic Research (NBER), July. 


\section{Annex A1}

\section{Short-run comparative statics}

Equations (5) and (6) in section II help to find solutions for consumption $c(t)$ and labour supply $l(t)$ as functions of marginal utility of wealth $\lambda(t)$, of capital stock $k(t)$ and of policy parameters $\alpha$ and $\beta$. Therefore, differentiating (5) and (6), we find that:

$$
\begin{gathered}
U_{c c} d c+U_{c l} d l=d k \\
U_{l c} d c+\left(U_{l l}+\lambda(1-\beta) f_{l l} h\right) d l=-\lambda(1-\beta) f_{k l} d k-(1-\beta) f i h d \lambda+\lambda(1-\beta) h^{\prime} \bar{g} d \alpha+\lambda f i h d \beta
\end{gathered}
$$

The solution to the system above originates the following short-run relations, as introduced in subsection II.1:

$$
\begin{gathered}
\frac{d c}{d k}=\frac{\lambda(1-\beta) f_{k} U_{c l} h}{\Delta}<0, \frac{d l}{d k}=-\frac{\lambda(1-\beta) f_{k} U_{c c} h}{\Delta}>0, \frac{d c}{d l}=\frac{U_{l l}+\lambda(1-\beta) f_{l l} h+(1-\beta) f_{i} h}{\Delta}<0, \\
\frac{d l}{d \lambda}=-\frac{(1-\beta) f_{i} U_{c c} h+U_{c}}{\Delta}>0, \frac{d c}{d \alpha}=-\frac{\lambda(1-\beta) f_{i l} U_{c l} \bar{g}}{\Delta}>0, \frac{d c}{d \beta}=-\frac{\lambda f U_{c l} h}{\Delta}>0 \text { and } \frac{d l}{d \beta}=\frac{\lambda f U_{c c} h}{\Delta}<0 .
\end{gathered}
$$

\section{Demonstration that long-run equilibrium is a saddle point}

The system of linearized equations (13) and (14) around the steady state may be written in matrix form as:

$$
\begin{gathered}
\dot{k}=w_{11}(k-\widetilde{k})+w_{12}(\lambda-\tilde{\lambda}) \\
\dot{\lambda}=-(1-\beta) \widetilde{\lambda} w_{12}(k-\widetilde{k})-(1-\beta) \widetilde{\lambda} w_{22}(\lambda-\widetilde{\lambda})
\end{gathered}
$$

In order to demonstrate that the system equilibrium is a saddle-point type, we still need to prove that the determinant of the system above is negative. Indeed, the determinant sign is $-\tilde{\lambda}(1-\beta)\left[w_{11} w_{22}-w_{21} w_{12}\right]<0, w_{11}>0, w_{22}>0, w_{12}>0, w_{21}<0$ and $0<\beta<1$. Besides, as $-\tilde{\lambda}(1-\beta)\left[w_{11} w_{22}-w_{12} w_{21}\right]=\mu_{1} \mu_{2}$, where $\mu_{1}$ and $\mu_{2}$ are the eigenvalues associated with the system matrix above, we shall admit without loss of generality that $\mu_{1}<0$ and $\mu_{2}>0$.

\section{Stable and unstable arms of saddle-point equilibrium, determination of trajectories of $k(t)$ and $\lambda(t)$ and $(t)$ jump}

It is accepted that the government can announce today a change in the fiscal policy at a future time $T>0$. In other words, the policy change is anticipated by agents. Initially, the solution for $k(t)$ and $\lambda(t)$ in the period $0 \leq t<T$ is as follows:

$$
\begin{gathered}
k(t)=\tilde{k}_{1}+A_{1} e^{\mu_{1} t}+A_{2} e^{\mu_{2} t} \\
\lambda(t)=\widetilde{\lambda}_{1}+A_{1}\left(\frac{\mu_{1}-w_{11}}{w_{12}}\right) e^{\mu_{1} t}+A_{2}\left(\frac{\mu_{2}-w_{11}}{w_{12}}\right) e^{\mu_{2} t}
\end{gathered}
$$


For the period $t \geq T$, the solutions for $k(t)$ and $\lambda(t)$ are:

$$
\begin{gathered}
k(t)=\widetilde{k} 2+A_{1}^{\prime} e^{\mu_{1} t}+A_{2}^{\prime} e^{\mu_{2} t} \\
\lambda(t)=\widetilde{\lambda}_{2}+A_{1}^{\prime}\left(\frac{\mu_{1}-w_{11}}{w_{12}}\right) e^{\mu_{1} t}+A_{2}^{\prime}\left(\frac{\mu_{2}-w_{11}}{w_{12}}\right) e^{\mu_{2} t}
\end{gathered}
$$

In order to meet the transversality condition (9), we consider that $A^{\prime}{ }_{2}=0$. Imposing this restriction on the two previous equations, we have the stable arm of the saddle-point equilibrium:

$$
\lambda(t)=\tilde{\lambda}_{2}+\left(\frac{\mu_{1}-w_{11}}{w_{12}}\right)(k(t)-\widetilde{K})
$$

where the angular coefficient of this straight line is negative, as $w_{11}>0, w_{12}>0, \mu_{1}<0$.

The unstable arm is obtained by replacing the stable root $\mu_{1}$ with the unstable root $\mu_{2}$ in the prior straight-line equation. Consequently,

$$
\lambda(t)=\widetilde{\lambda}_{2}+\left(\frac{\mu_{2}-w_{11}}{w_{12}}\right)(k(t)-\widetilde{K})
$$

The angular coefficient of the unstable arm line is positive, as according to the eigenvalue properties $\left(\frac{\mu_{2}-w_{11}}{w_{12}}\right)=\left(\frac{-\tilde{\lambda}(1-\beta) w_{21}}{\mu_{2}+\tilde{\lambda}(1-\beta)_{22}}\right)$, considering that $w_{21}<0, w_{22}>0$ and $\mu_{2}>0$.

In order to obtain the trajectories of $k(t)$ and $\lambda(t)$, we need to determine the constants $A_{1}, A_{2}$ and $A_{1}{ }_{1}$ as $A^{\prime}{ }_{2}=0$. For this purpose we have developed two additional hypotheses: the first is that the initial capital stock (date $t=0$ ) is equal to the initial steady-state capital stock, which is $k(0)=\widetilde{k} 1$; the second is that on the date of the policy change $(t=T)$ there is a continuity of solutions, which means that they must be similar for this period of time.

Therefore, on the basis of the first hypothesis, $k(0)=\widetilde{k} 1+A_{1}+A_{2}$ which implies that $A_{1}+A_{2}=0$ or $A_{1}=-A_{2}$. The second hypothesis originates the following equation system:

$$
\begin{gathered}
\left(A_{1}^{\prime}-A_{1}\right)\left(\frac{\mu_{1}-w_{11}}{w_{12}}\right) e^{\mu_{1} t}+A_{2}\left(\frac{\mu_{2}-w_{11}}{w_{12}}\right) e^{\mu_{2} T}=\widetilde{\lambda}_{2}-\tilde{\lambda}_{1} \\
\left(A_{1}^{\prime}-A_{1}\right) e^{\mu_{1} T}+A_{2} e^{\mu_{2} T}=\widetilde{k} 2-\widetilde{k}_{2}
\end{gathered}
$$

Therefore, the solution to the system above, besides using the restriction $A_{1}=-A_{2}$ produces the following solutions:

$$
\begin{gathered}
A_{1}=\frac{e^{\mu_{1} T}\left[\left(\frac{\mu_{1}-w_{11}}{w_{12}}\right)\left(\widetilde{k}_{2}-\widetilde{k}_{2}\right)-\left(\tilde{\lambda}_{2}-\tilde{\lambda}_{1}\right)\right]}{\Delta} \\
A_{1}^{\prime}=\frac{e^{\mu_{1} T}\left[\left(\frac{\mu_{1}-w_{11}}{w_{12}}\right)\left(\widetilde{k}_{2}-\widetilde{k}_{2}\right)-\left(\tilde{\lambda}_{2}-\tilde{\lambda}_{1}\right)\right]+e^{\mu_{2} T}\left[\left(\widetilde{\lambda}_{2}-\widetilde{\lambda}_{1}\right)-\left(\frac{\mu_{2}-w_{11}}{w_{12}}\right)\left(\widetilde{k}_{2}-\widetilde{k}_{1}\right)\right]}{\Delta}
\end{gathered}
$$

where $\Delta=e^{\left(\mu_{1}+\mu_{2}\right) T}\left(\frac{\mu_{2}-\mu_{1}}{w_{12}}\right)>0$.

Thus, replacing $A_{1}, A_{2}$ and $A_{1}^{\prime}$ in the expressions of $k(t)$ and $\lambda(t)$ for each of the periods $0 \leq t<T$ and $t \geq T$, we fully determine the trajectories of $k(t)$ and $\lambda(t)$.

In determining the solution for this model type, it is generally admitted that one of the variables may jump with each new measure announced by the government while the other will continuously evolve through time. For this article, the first variable shall be the marginal utility of wealth $\lambda(t)$. The variable $k(t)$ shall be the predetermined variable that continuously evolves through time. 
In order to calculate the dimension of this jump, it is sufficient to have $\mathrm{t}=0$ in the equation of $\lambda(t)$ for a period $0 \leq t<T$ observing that $A_{1}=-A_{2}$. Hence, we find that:

$$
\lambda(0)=\tilde{\lambda}_{1}+A_{2}\left(\frac{\mu_{2}-\mu_{1}}{w_{12}}\right)
$$

Replacing the value of $A_{2}$ in this last expression, we obtain the expression for the $\lambda(t)$ jump:

$$
\lambda(0)-\tilde{\lambda}_{1}=e^{-\mu_{2} T}\left[\left(\tilde{\lambda}_{2}-\tilde{\lambda}_{1}\right)-\left(\frac{\mu_{1}-w_{11}}{w_{12}}\right)\left(\widetilde{k}_{2}-\widetilde{k}_{1}\right)\right]
$$

Regardless of the sign of the expression between brackets in the previous equation, the longer the time $T$, in other words the more distant the policy change announced, the lower the resulting $\lambda(t)$ jump.

When the policy change occurs immediately (today), which means that it is not anticipated by agents, the $\lambda(t)$ jump is calculated by making $T=0$. Hence, we have that:

$$
\lambda(0)=\tilde{\lambda}_{2}-\left(\frac{\mu_{1}-w_{1}}{w_{12}}\right)\left(\widetilde{k}_{2}-\tilde{k}_{1}\right)
$$

which is just the stable arm expression. This implies that when the policy announcement is not anticipated, $\lambda(t)$ immediately jumps to the straight line of the stable arm saddle-point equilibrium.

The essential characteristic of solutions in this type of model is that the dynamics involve three phases. An announcement today on a policy alteration at a future time $T$ generates an immediate jump in $\lambda(t)$. The further in the future the policy change, the weaker the intensity of the jump. Immediately afterward, these variables follow unstable trajectories until meeting the stable arm saddle-point equilibrium in a period $T$. As from this point, these variables continue on the stable arm until reaching the new steady-state equilibrium.

When the policy change announcement and its implementation are immediate, the marginal utility of wealth jumps immediately to the stable arm and is then followed by $k(t)$ and $\lambda(t)$ in its trajectory through the stable arm towards the new steady-state equilibrium.

\section{Formal solution to the equation $\dot{P}(t)-r(t) P(t)=-1$ looking into the future}

The general solution for this differential equation is given by the following expression:

$$
P(t)=e_{0}^{s} r(t) d t A-\int_{0}^{t} e_{0}^{-\int_{0}^{t} r(s) d s} d s
$$

where $A$ is a constant to be determined. In order to ensure that this constant is endogenously established, Sargent and Wallace (1973) proposed the application of the terminal condition instead of the initial condition. The terminal condition is that the price level should remain limited when $t \rightarrow \infty$. For this purpose, we must have that:

$$
A=\lim _{t \rightarrow \infty} \int_{0}^{t} e^{-\int_{0}^{t} r(s) d s} d s=\int_{0}^{\infty} e^{-\int_{0}^{t} r(s) d s} d s
$$

Replacing this last result in the expression $P(t)$, we find that:

Provided $R(t)=\frac{1}{P(t)}$, we finally find that:

$$
P(t)=e_{0}^{s} r(t) d t\left[\int_{t}^{\infty} e_{0}^{-\int_{0}^{t} r(w) d w} d s\right]=\int_{t}^{\infty} e_{t}^{-\int_{t}^{s} r(w) d w} d s
$$

$$
R(t)=\frac{1}{\int_{t}^{\infty} e_{t}^{-\int_{t}^{s} r(w) d w} d s}
$$




\section{Demonstration of proposition 1}

Proposition 1: suppose that conditions (17) - (19) are met. Then:
(a) $l(0)=\left[\frac{s_{0}}{\beta A k_{0}^{\delta}((1-\alpha) \bar{g})^{\eta}}\right]^{\frac{1}{1-\delta}}$;
(b) $c(0)=\frac{\gamma(1-\delta) s_{0}(1-l(0))}{\beta(1-\gamma) l(0)}$;
(c) $\tilde{c}=\frac{\tilde{s}-\beta \bar{g}}{\beta}$;
(d) $\tilde{l}=\frac{(1-\gamma)(\tilde{s}-\beta \bar{g})}{(1-\gamma)(\tilde{s}-\beta \bar{g})+\gamma(1-\delta)(1-\beta) \tilde{s}}$;
(e) $\tilde{k}=\frac{(1-\beta) \delta \tilde{s}}{\rho \beta}$.

Demonstration:

(a) $\ln t=0$, we have that:

$$
\beta A k_{0}^{\delta} l(0)^{1-\delta}((1-\alpha) \bar{g})^{\eta}=s_{0}
$$

Resolving A.1 for $l(0)$, we obtain the desired result.

(b) Using the utility and technology utility functions, equations (5) and (6) may be written as:

$$
\begin{gathered}
\gamma c^{\gamma(1-\sigma)-1}(1-l)^{(1-\gamma)(1-\sigma)}=\lambda \\
(1-\gamma) c^{\gamma(1-\sigma)}(1-l)^{(1-\gamma)(1-\sigma)-1}=\lambda(1-\delta) A k^{\delta} l^{(1-\delta)-1}((1-\alpha) \bar{g})^{\eta}
\end{gathered}
$$

Combining (A.2) and (A.3) in $t=0$ and using the definition of $y$, we have that:

$$
\left(\frac{1-\gamma}{\gamma}\right) \frac{l(0) c(0)}{(1-l(0))}=(1-\delta) y(0)
$$

The result is demonstrated by considering the assumption that $y(0)=s_{0} / \beta$ and item (a) in equation (A.4).

In this situation, first-order conditions (5) and (6) together with the equations that describe the steady-state equilibrium produce the following system:

$$
\begin{aligned}
(1-\beta) \tilde{y} & =\tilde{c}+\bar{g} \\
\left(\frac{1-\gamma}{\gamma}\right) \frac{\tilde{l} \tilde{c}}{(1-\tilde{l})} & =(1-\beta)(1-\delta) \tilde{y} \\
\tilde{y} & =\frac{\tilde{s}}{\beta}
\end{aligned}
$$

The solution to the system above results in the proposition results described in items (c), (d) and (e). 


\section{First-order conditions to the problem (18)}

By definition, first-order conditions for $\alpha$ and $\beta$ in problem (18) respectively determine that:

$$
\begin{aligned}
& \tau \frac{\partial U(0)}{\partial \alpha}+(1-\tau) \frac{\partial \widetilde{U}}{\partial \alpha}=0 \\
& \tau \frac{\partial U(0)}{\partial \beta}+(1-\tau) \frac{\partial \widetilde{U}}{\partial \beta}=0
\end{aligned}
$$

Consequently, in order to set equations (20) and (21), it is sufficient to find derivatives appointed in (A.5) and (A.6). Using the expression for $U(0)$, we have that:

$$
\begin{gathered}
\frac{\partial U(0)}{\partial \alpha}=\left[\frac{\gamma(1-\delta)}{\beta(1-\gamma)}\right]^{\gamma(1-\sigma)} s^{\frac{\gamma \delta(1-\sigma)}{1-\delta}} \\
\frac{\partial U(0)}{\partial \alpha}=\left[\frac{\gamma(1-\delta)}{\beta(1-\gamma)}\right]^{\gamma(1-\delta)} s_{0}^{\frac{\gamma \delta(1-\delta)}{1-\delta}} \frac{\left(\frac{1-\sigma}{1-\delta}\right)\left[\phi(\alpha)^{\frac{1}{1-\delta}}-s_{0}^{\frac{1}{1-\delta}}\right]^{-\sigma} \phi(\alpha)^{\frac{(1-\gamma)(1-\sigma)}{1-\delta}} \phi^{\prime}(\alpha)\left[\gamma \phi(\alpha)^{\frac{1}{1-\delta}}+(1-\gamma) s_{0}^{\frac{1}{1-\delta}}\right]}{\phi(\alpha)^{2 \frac{(1-\gamma)(1-\sigma)}{1-\delta}}}+\frac{\varphi}{\alpha}
\end{gathered}
$$

It is easy to verify that $\phi^{\prime}(\alpha)=-\eta \phi(\alpha) /(1-\alpha)$. Using this fact in the expression above we arrive at:

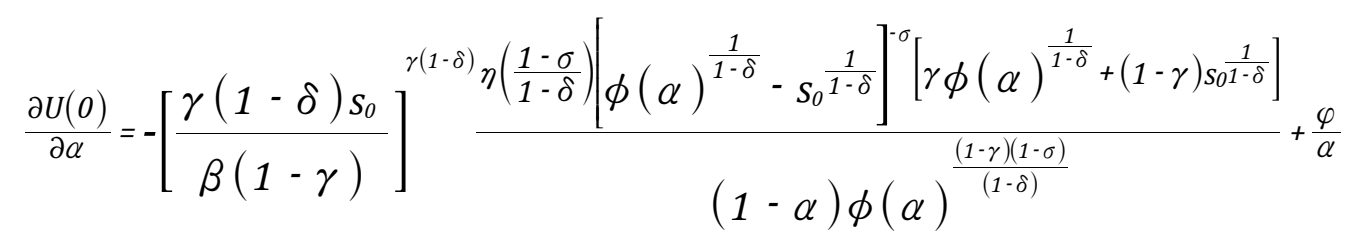

On the other hand:

$$
\frac{\partial \widetilde{U}}{\partial \alpha}=\frac{\varphi}{\alpha}
$$

Replacing (A.7) and (A.8) in (A.5), we obtain equation (20). Proceeding likewise with regard to $\beta$, we have that:

$$
\frac{\partial U(0)}{\partial \beta}=-\gamma \beta^{-1}\left[\frac{\gamma(1-\delta)^{\gamma(1-\sigma)}}{\beta(1-\gamma)} s_{0}^{\frac{\gamma \delta(1-\sigma)}{(1-\delta)}} \frac{\left[\phi(\alpha)^{\frac{1}{(1-\delta)}}-s_{0}^{\frac{1}{(1-\delta)}}\right]^{1-\sigma}}{\phi(\alpha)^{\frac{(1-\gamma)(1-\sigma)}{(1-\sigma)}}}\right.
$$

We also have that:

$$
\begin{gathered}
\frac{\partial \widetilde{U}}{\partial \beta}=-\frac{\gamma(1-\sigma)(1-\gamma)^{(1-\gamma)(1-\sigma)} \beta^{-\gamma(1-\sigma)}(\tilde{s}-\beta \bar{g})^{(1-\sigma)}}{(1-\sigma)[(1-\gamma)(\tilde{s}-\beta \bar{g})+\gamma(1-\delta)(1-\beta) \tilde{s}]}+ \\
+\frac{(1-\gamma)^{(1-\gamma)(1-\sigma)} \beta^{\gamma(1-\sigma)}(1-\sigma)(\tilde{s}-\beta \bar{g})^{-\sigma}[(1-\sigma)(\tilde{s}-\beta \bar{g})+\delta \sigma(1-\beta) \tilde{s}]^{(1-\gamma)(1-\sigma)-1}}{(1-\sigma)} \times
\end{gathered}
$$




$$
\frac{\{[(1-\gamma) \delta \sigma \tilde{s}-\gamma(1-\sigma) \bar{g}](\tilde{s}-\beta \bar{g})-\delta \sigma(1-\beta) \tilde{s} \bar{g}\}}{[(1-\sigma)(\tilde{s}-\beta \bar{g})+\delta \sigma(1-\beta) \tilde{s}]^{2(1-\gamma)(1-\sigma)}}
$$

Replacing (A.9) and (A.10) in (A.6), after some algebraic manipulations we obtain equation (21).

\section{Demonstration of proposition 2}

Proposition 2: If $\eta>\left|\left(\frac{1-\gamma}{\gamma}\right)^{\gamma(1-\sigma)}\right| / \tau(1-\sigma)$ and $l(0)>(0.5)^{1-\delta}$, then $\widehat{\alpha}<0.5$.

Demonstration:

It is enough to prove that in the enunciation conditions, the left side (22) is higher than one. Initially, observe that the term $\left[\frac{\tau \eta(1-\sigma)}{(1-\delta)}\right]\left[\frac{\gamma(1-\delta) s_{0}}{\widehat{\beta}(1-\gamma)}\right]^{\gamma(1-\sigma)}$ is higher than one.

This occurs because of the assumption that $\eta>\left(\frac{1-\gamma}{\gamma}\right)^{\gamma(1-\sigma)} / \tau(1-\sigma)$ and the fact that $\frac{S 0}{\beta}=y_{0}>1$. Therefore, the result is established if we can prove that:

$$
\frac{\left[\phi(\alpha)^{\frac{1}{1-\delta}}-s_{0} \frac{1}{1-\delta}\right]^{-\sigma}\left[\gamma \phi(\widehat{\alpha})^{\frac{1}{1-\delta}}+(1-\gamma) s_{0}^{\frac{1}{1-\delta}}\right]}{\phi(\widehat{\alpha})^{\frac{(1-\gamma)(1-\sigma)}{(1-\delta)}}}>1
$$

Applying a reduction ad absurdum, let us assume this affirmation is not valid. In this case we have that:

$$
\left[\gamma \phi(\widehat{\alpha})^{\frac{1}{1-\delta}}+(1-\gamma) s_{0}^{\left.\frac{1}{1-\delta}\right]} \leq\left[\phi(\widehat{\alpha})^{\frac{1}{1-\delta}}-s_{0}^{\frac{1}{1-\delta}}\right]^{\sigma} \phi(\widehat{\alpha})^{\frac{(1-\gamma)(1-\sigma)}{1-\delta}}\right.
$$

As $l(0)<1$, we can easily demonstrate that $\varphi(\widehat{\alpha})>$ so. Following some manipulations, the inequality in (A.10) may be rewritten as:

$$
s_{0}^{\frac{1}{1-\delta}}<\left[1-\left(\frac{s_{0}}{\phi(\widehat{\alpha})}\right)^{\frac{1}{1-\delta}}\right] \sigma(\widehat{\alpha})^{\frac{1-\gamma(1-\sigma)}{1-\delta}}
$$

or even:

$$
\left(\frac{s_{0}}{\phi(\widehat{\alpha})}\right)^{\frac{1}{1-\delta}}<\left[1-\left(\frac{s_{0}}{\phi(\widehat{\alpha})}\right)^{\frac{1}{1-\delta}}\right] \sigma \phi(\widehat{\alpha})^{\frac{1-\gamma(1-\sigma)}{1-\delta}}
$$


Given that $\frac{s_{0}}{\phi(\widehat{\alpha})}=l(0)$, equation (A.11) may be rewritten as:

$$
l(0)^{\frac{1}{1-\delta}}<\left[1-l(0)^{\frac{1}{1-\delta}}\right]^{\sigma} \phi(\widehat{\alpha})^{\frac{-\gamma(1-\sigma)}{1-\delta}}
$$

For $\sigma<1$, it is evident that $\left[1-l(0)^{\frac{1}{1-\delta}}\right]^{\sigma}<1-l(0)^{\frac{1}{1-\sigma}}$. In this case, equation (A.12) implies that: $\frac{l(0)^{\frac{1}{1-\delta}}}{\left(1-l(0)^{\frac{1}{1-\delta}}\right)}<\phi(\widehat{\alpha})^{\frac{-\gamma(1-\sigma)}{1-\delta}}$

Given the proposition conditions and using the definition of $\phi(\alpha)$, we have that: $\frac{l(0)^{\frac{1}{1-\delta}}}{\left(1-l(0)^{\frac{1}{1-\delta}}\right)}<\phi(\widehat{\alpha})^{\frac{-\gamma(1-\sigma)}{1-\delta}}$. That contradiction produces the desired result. 